\title{
Simple Estimation of Bosentan in Tablet Formulation by RP-HPLC
}

\author{
Selvadurai Muralidharan*, Jaya Raja Kumar \\ Faculty of Pharmacy, AIMST University, Bedong, Malaysia \\ Email: *murali23pharm@hotmail.com
}

Received September 25, 2012; revised October 27, 2012; accepted November 3, 2012

\begin{abstract}
A simple, precise, and accurate method is developed and validated for the analysis of Bosentan tablet formulation. The method has shown adequate separation of the ingredients from Tablets. Separation was achieved on a $\mathrm{C}_{18}$ column using a mobile phase consisting of acetonitrile: $10 \mathrm{Mm}$ ammonium acetate $(\mathrm{pH} 4.5)$ buffer $(70: 30, \mathrm{v} / \mathrm{v})$ at a flow rate of 1.0 $\mathrm{ml} / \mathrm{min}$ and UV detection at $265 \mathrm{~nm}$. This new method is validated as per the ICH, which includes accuracy, precision, selectivity, linearity and range, robustness and ruggedness. The current method demonstrates good linearity over the range of $5-70 \mathrm{ng} / \mathrm{ml}$ of bosentan with $\mathrm{r}^{2}$ of 0.999 . The average recovery of the method is $98.6 \%$. The degree of reproducibility of the results obtained as an outcome of small deliberate variations in the method parameters and by changing analytical operator has proven that this method is robust and rugged.
\end{abstract}

Keywords: Estimation; Validation; RP-HPLC; Bosentan

\section{Introduction}

Bosentan is competitive antagonist of endothelin-1 receptor acts on endothelin A and endothelin present smooth mussels of pulmonary blood vessels [1-3]. Bosentan used in the treatment pulmonary hypertension and digital ulcers in patients with systemic sclerosis. Chemically it contain 4-tertbutyl-N-[6-(2-hydroxyethoxy)-5-(2-ethoxyphenoxy)-2-(pyrimidin-2-yl) pyrimidin-4-yl] benzene-1sulfonamide. Limited method has been reported only for spectroscopy and LC-MS-MS (Liquid Chromatography with Tandem Mass Spectrometry) [4-9]. As per our knowledge, no other method is available which is based on RP-HPLC (Reverse Phase-high Performance Liquid Chromatography) estimation. Therefore, it is very imperative to develop a simple and suitable analytical method for the measurement of bosentan and related compounds in bulk and in formulations. Such methods could be easily adapted for routine and in-process quality control analysis, dissolution or similar studies. Due to the importance of bioequivalence of the dosage forms and limitations of UV spectrophotometric methods in detection of impurities, our purpose was to develop a simple, sensitive, and reliable method for simultaneous determination of the drug and respective impurities which can be applied in quality control laboratories.

Validation of the current method was conducted for

${ }^{*}$ Corresponding author. these ingredients which include accuracy, precision, selectivity, linearity and range, robustness and ruggedness.

\section{Experimental}

\subsection{Chemicals}

Acetonitrile, Methanol HPLC grade and AR grade ammonium dihydrogen phosphate are from Merck (Darmstadt, Germany). Bosentan was obtained as a gift sample from Sashan chemicals India.

\subsection{Apparatus}

HPLC chromatographic separation was performed on a Shimadzu liquid chromatographic system equipped with a LC-20AD solvent delivery system (pump), SPD-20A photo diode array detector, and SIL-20ACHT injector with $50 \mu \mathrm{L}$ loop volume. LC solution version 1.25 was applied for data collecting and processing (Shimadzu, Japan).

\subsection{Reference Standard Solutions}

Reference standard solution was prepared by dissolving $100 \mathrm{mg}$ of bosentan in $100 \mathrm{ml}$ of methanol. Nominal standard solution was prepared by diluting $5 \mathrm{ml}$ of stock standard solution to $50 \mathrm{ml}$ with mobile phase to obtain a solution having a known concentration of $100 \mathrm{mcg} / \mathrm{ml}$. Nominal solutions of the formulated tablets were prepared by dissolving a quantity of the powdered tablet equivalent to $62.5 \mathrm{mg}$ of bosentan in $100 \mathrm{ml}$ of mobile 
phase to get the same concentration as in the standard solution.

\section{Results and Discussion}

\subsection{Method Development}

Preliminary studies involved trying $\mathrm{C}_{18}$ columns and testing several mobile phase compositions for the effective separation of bosentan. Reverse phase column eluted with a mobile phase of acetonitrile/ammonium acetate buffer $(70: 30, \mathrm{v} / \mathrm{v})$ at a flow rate of $1.0 \mathrm{ml} / \mathrm{min}$ and a detection wavelength of $265 \mathrm{~nm}$ afforded the best separation of these analytes. The sample chromatogram of Bosentan is presented in Figure 1.

\subsection{Method Validation}

After the method development [10], the validation of the current method has been performed in accordance with USP requirements for assay determination (Category-I: analytical methods for quantitation of active ingredients in finished pharmaceutical products) which include accuracy, precision, selectivity, linearity and range, robustness and ruggedness.

\subsection{Linearity and Range}

Linearity of this method, different concentrations of the four analytes in the range of $5-70 \mathrm{ng} / \mathrm{ml}$ for bosentan was analyzed and the linearity between the peak-area and the concentration was examined for each analyte. The results obtained show that the current method is linear for the three analytes in the range specified above with a correlation coefficient of better than 0.99 (Table 1 and Figure 2).

\subsection{Accuracy}

Accuracy of the method was studied by preparing the placebo of the drug tablet formulation according to the formulation procedure. To the required quantity of placebo, a known quantity of the four active ingredients (bosentan) with the same proportion as in the drug formulation was added to get simulated drug formulation. Results have shown that the mean recovery of the assay is within $100 \% \pm 2.0 \%$ for bosentan, and the $\% \mathrm{CV}$ is lower than $1.0 \%$ (Table 2).

\subsection{Precision}

The precision of this method was evaluated by calculateing the \% $\mathrm{CV}$ of the peak areas of six replicate injections of the nominal standard solution of bosentan. Furthermore, the \% $\mathrm{CV}$ of three replicates of the recovery data analyzed in accuracy study was calculated, and it was found to be less than 2.0\% (Tables 3(a) and (b)). These results show that the current method is repeatable.

\subsection{Selectivity}

Selectivity of the current method was demonstrated by good separation of the four analytes from each other. Furthermore, excipient of the tablet formulation did not interfere with the active ingredients of the drug product.

\subsection{Limit of Detection (LOD) and Limit of Quantitation (LOQ)}

The LOD and LOQ for bosentan were predicted basing on the parameters of standard error of estimate and slope, calculated from linearity of the response data of bosentan $2.0 \mathrm{ng} / \mathrm{ml}$ and $7.0 \mathrm{ng} / \mathrm{ml}$ respectively.

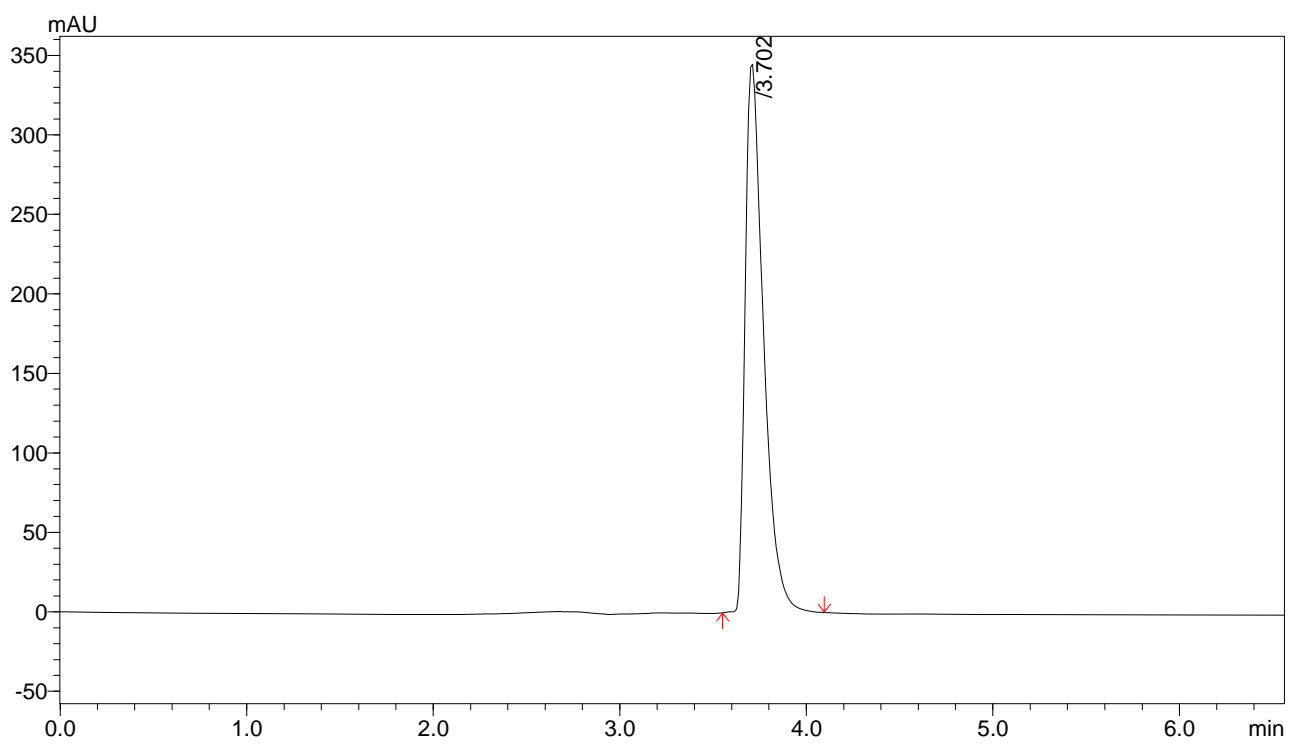

Figure 1. Typical chromatogram of bosentan sample. 
Table 1. Results of calibration curve at $265 \mathrm{~nm}$ for bosentan by HPLC.

\begin{tabular}{ccc}
\hline SI. No. & Concentration $(\mathrm{ng} / \mathrm{ml})$ & Peak area \\
\hline 1 & 5 & 377,485 \\
2 & 10 & 751,236 \\
3 & 15 & $1,085,317$ \\
4 & 20 & $1,508,754$ \\
5 & 30 & $2,253,762$ \\
6 & 70 & $5,279,853$ \\
\hline
\end{tabular}

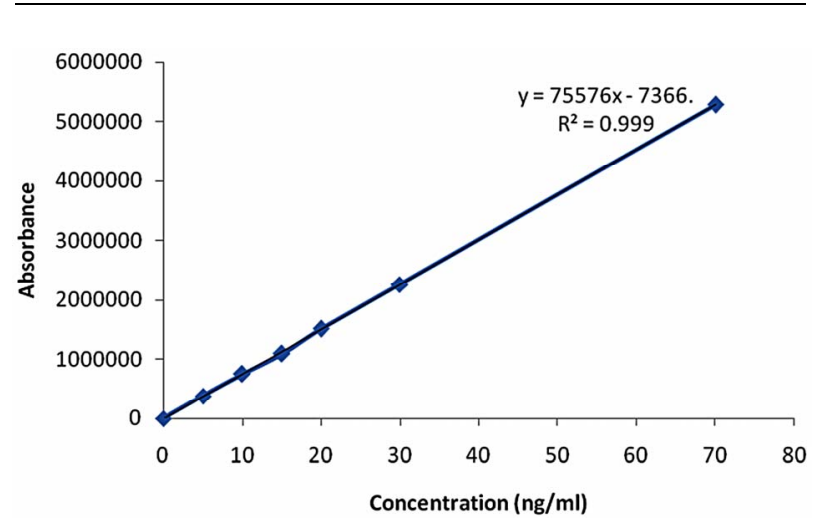

Figure 2. Calibration curve of bosentan.

Table 2. Accuracy studies of bosentan.

\begin{tabular}{cccc}
\hline & $5 \mathrm{ng} / \mathrm{ml}$ & $20 \mathrm{ng} / \mathrm{ml}$ & $70 \mathrm{ng} / \mathrm{ml}$ \\
\hline & 4.8532 & 19.6524 & 69.5247 \\
& 4.9102 & 19.8647 & 69.9965 \\
& 4.7623 & 19.9102 & 69.8749 \\
& 4.6875 & 19.9975 & 69.9941 \\
Mean & 4.8472 & 19.6748 & 69.8728 \\
\hline \% & 4.8120 & 19.8199 & 69.8526 \\
\% Accuracy & 0.087 & 0.150 & 0.193 \\
\hline
\end{tabular}

\subsection{Recovery Studies}

The recovery studies were carried out using specified concentration range and the percentage recovery of bosentan. The results are presented in the Table 4.

\subsection{Solution Stability}

In order to demonstrate the stability of standard and sample solutions during analysis, both solutions were analyzed over a period of $5 \mathrm{~h}$ at room temperature. The results show that for both solutions, the retention time and peak area of bosentan remained almost unchanged and
Table 3. (a) Precision result of bosentan (Intraday result); (b) Interday result.

(a)

\begin{tabular}{cccc}
\hline & $5 \mathrm{ng} / \mathrm{ml}$ & $20 \mathrm{ng} / \mathrm{ml}$ & $70 \mathrm{ng} / \mathrm{ml}$ \\
\hline & 4.8956 & 19.6532 & 69.9652 \\
& 4.8356 & 19.8652 & 69.6358 \\
& 4.7092 & 19.7423 & 69.8742 \\
& 4.6985 & 19.6348 & 69.8634 \\
& 4.9012 & 19.9552 & 69.8721 \\
\hline Mean & 4.8080 & 19.7701 & 69.8421 \\
\%D CV & 0.098 & 0.137 & 0.122 \\
\% Accuracy & 2.050 & 0.697 & 0.175 \\
\hline & 96.16 & 98.85 & 99.77 \\
\hline & & & \\
\hline & $5 \mathrm{ng} / \mathrm{ml}$ & $20 \mathrm{ng} / \mathrm{ml}$ & $70 \mathrm{ng} / \mathrm{ml}$ \\
\hline \% Accuracy & 4.6592 & 19.8562 & 69.5628 \\
\hline SD & 4.7843 & 19.9217 & 69.9127 \\
\hline & 4.8821 & 19.7852 & 69.8594 \\
& 4.7526 & 19.8831 & 69.7549 \\
& 4.9102 & 19.7541 & 69.9012 \\
\hline
\end{tabular}

Table 4. Recovery studies of bosentan.

\begin{tabular}{ccc}
\hline $\begin{array}{c}\text { Amount of sample } \\
(\mathrm{ng} / \mathrm{ml})\end{array}$ & $\begin{array}{c}\text { Amount of drug added } \\
(\mathrm{ng} / \mathrm{ml})\end{array}$ & $\begin{array}{c}\text { Amount }^{*} \\
\operatorname{Recovered}^{*}(\mathrm{ng} / \mathrm{ml})\end{array}$ \\
\hline 10 & 1 & 10.65 \\
10 & 2 & 12.48 \\
10 & 3 & 12.86 \\
10 & 4 & 13.98 \\
10 & 5 & 14.97 \\
\hline$* *$ Average of five determinations. & &
\end{tabular}

no significant degradation within the specified period, thus indicated that both solutions were stable for at least $5 \mathrm{~h}$, which was sufficient to complete the whole analytical process.

\subsection{System Suitability Studies}

The column efficiency, resolution and peak asymmetry were calculated for the standard solutions. The values obtained demonstrated the suitability of the system for the analysis of this drug and the system suitability parameters fall within $\pm 3 \%$ standard deviation range during routine performance of the method. The results are pre- 
sented in Table 5.

\subsection{Robustness and Ruggedness}

Robustness of an analytical method is a measure of its capacity to remain unaffected by small but deliberate variations in method parameters, and provides an indication of its reliability during normal usage. Robustness of the current method was investigated by analyzing samples of the drug product using the same chromatographic conditions set forth in method development but with a small change in the chromatographic parameters (Table 6). Ruggedness of the current method was demonstrated by analyzing six samples (assay) of tablet formulation by two analysts in the same laboratory.

\section{Conclusion}

Proposed study describes new reverse phase high performance liquid chromatographic method for the estimation of bosentan in formulation. The method was validated and found to be simple, sensitive, accurate and pre-

Table 5. System suitability studies.

\begin{tabular}{cc}
\hline Parameters & Bosantan \\
\hline Linearity range & $5-70 \mathrm{ng} / \mathrm{ml}$ \\
Regression equation & $75576 \mathrm{x}-736$ \\
Correlation coefficient $\left(\mathrm{r}^{2}\right)$ & 0.999 \\
Theoretical plate/meter & 2600 \\
Asymmetry & 1.35 \\
Capacity factor $(k)$ & 1.9 \\
\hline
\end{tabular}

Table 6. Robustness testing of bosentan.

\begin{tabular}{ccc}
\hline Parameters & & Bosentan \\
\hline \% Acetonitrile & 86 & 98.5 \\
& 85 & 97.8 \\
Flow rate $(\mathrm{ml} / \mathrm{min})$ & 87 & 99.9 \\
& 1.3 & 99.6 \\
& 1.5 & 97.2 \\
Wave length $(\mathrm{nm})$ & 1.7 & 98.9 \\
& 250 & 98.5 \\
Assay average & 260 & 99.5 \\
& 265 & 99.9 \\
\hline
\end{tabular}

cise. Percentage of recovery studies shows that, the method is free from interference of the other active ingredients and additives used in the formulation. The simplicity of the method allows for application in laboratories that lack sophisticated analytical instruments such as LC-MS/MS or GC-MS/MS that are complicated, costly and time consuming rather than a simple HPLC-UV method. Thus the proposed method could be useful for the national quality control laboratories in several underdeveloped and developing countries.

\section{REFERENCES}

[1] www.wikipedia.org/wiki/Bosentan

[2] www.drugbank.ca/drugs/DB00559

[3] www.chemblink.com/products/147536-97-8.htm

[4] B. Lausecker, B. Hess, G. Fischer, M. Mueller and G. Hopfgartner, "Simultaneous Determination of Bosentan and Its Three Major Metabolites in Various Biological Matrices and Species Using Narrow Bore Liquid Chromatography with Ion Spray Tandem Mass Spectrometric Detection," Journal of Chromatography B: Biomedical Sciences and Applications, Vol. 749, No. 1, 2000, pp. 6783. doi:10.1016/S0378-4347(00)00386-8

[5] A. S. Jadhav, B. S. Landge, S. L. Jadhav, N. C. Niphade, S. R. Bembalkar and V. T. Mathad, "Stability-Indicating Gradient RP-LC Method for the Determination of Process and Degradation Impurities in Bosentan Monohydrate: An Endothelin Receptor Antagonist," Chromatography Research International, Vol. 2011, 2011.

[6] M. M. Annapurna, S. P. S. Bisht, B. V. V. R. Kumar, V. R. Kumar and A. Narendra, "Spectrophotometric Determination of Bosentan and Its Application in Pharmaceutical Analysis," International Journal of Comprehensive Pharmacy, Vol. 2, No. 2, 2011.

[7] M. A. Gatzoulis, M. Beghetti, N. Galiè, J. Granton, R. M. F. Berger, A. Lauer, E. Chiossi and M. Landzberg, "LongerTerm Bosentan Therapy Improves Functional Capacity in Eisenmenger Syndrome: Results of the BREATHE-5 Open-Label Extension Study," International Journal of Cardiology, Vol. 27, No. 1, 2008, pp. 27-32.

[8] J. M. Parekh, D. K. Shah, M. Sanyal, M. Yadav and P. S. Shrivastav, "Development of an SPE-LC-MS/MS Method for Simultaneous Quantification of Bosentan and Its Active Metabolite Hydroxybosentan in Human Plasma to Support a Bioequivalence Study," Journal of Pharmaceutical and Biomedical Analysis, Vol. 70, 2012, pp. 462-470.

[9] G. Bansal, R. Singh, B. Saini and Y. Bansal, "ESI-MS(n) and LC-ESI-MS Studies to Characterize Forced Degradation Products of Bosentan and a Validated Stability-Indicating LC-UV Method," Journal of Pharmaceutical and Biomedical Analysis, in Press.

[10] Center for Drug Evaluation and Research (CDER), "Q2B Validation of Analytical Procedures: Methodology," Center for Drug Evaluation and Research. 